\title{
ICOM \\ Complexity, transparency and time pressure: practical insights into science communication in times of crisis
}

\author{
Jana Lasser, Verena Ahne, Georg Heiler, Peter Klimek, Hannah Metzler, \\ Tobias Reisch, Martin Sprenger, Stefan Thurner and Johannes Sorger
}

\begin{abstract}
A global crisis such as the COVID-19 pandemic that started in early 2020 poses significant challenges for how research is conducted and communicated. We present four case studies from the perspective of an interdisciplinary research institution that switched to "corona-mode" during the first two months of the crisis, focussing all its capacities on COVID-19-related issues, communicating to the public directly and via media, as well as actively advising the national government. The case studies highlight the challenges posed by the increased time pressure, high demand for transparency, and communication of complexity and uncertainty. The article gives insights into how these challenges were addressed in our research institution and how science communication in general can be managed during a crisis.
\end{abstract}

Keywords

DOI

Introduction
Risk communication; Science and policy-making; Visual communication

https://doi.org/10.22323/2.19050801

Submitted: 29th June 2020

Accepted: 1st September 2020

Published: 30th September 2020

How will the number of infections with the novel SARS-CoV-2 virus develop and when will the maximum capacity of the healthcare system be reached? How is the population reacting to governmental countermeasures to curb the spread of the virus? Which regions have an increased risk of infections? These are only some of the questions that researchers were asked to answer during the currently ongoing COVID-19 pandemic.

In this practice insight, we present four case studies exemplifying the communication of SARS-CoV-2-related research to policymakers, media and the public. The research was conducted at the Complexity Science Hub Vienna (CSH), a research institution actively engaged in advising the Austrian government as part of a scientific advisory board during the COVID-19 pandemic. Researchers at the CSH link state-of-the-art mathematics, modelling, data and computer science with fundamental questions in various disciplines, such as medicine, economics, 
ecology, or social sciences. At the onset of the pandemic in Austria around 14 March, day-to-day research was halted and the CSH switched to "corona-mode", directing all research activities to answer questions such as the ones posed above.

The challenges that arose from the special circumstances of the ongoing pandemic included (i) sharply increased time pressure and communication frequency, (ii) the need for increased transparency under the restrictions of data protection and confidentiality, and (iii) the increased need to communicate complex information, such as statistical uncertainties, while also offering "easy-to-follow" practical advice. We thereby take into account the reception of our research results from the perspective of policymakers as well as the media and the general public. We also discuss the design considerations and tradeoffs regarding the visual aspects of our communication.

\section{Time pressure}

Many crises that feature significant direct involvement of researchers to solve imminent problems are one-off events like earthquakes, where the "critical period" [Stein, 2004] of the disaster is too short for researchers to engage. Researchers are only involved to help alleviate consequences after the event has happened or to predict future events. On the other end of the spectrum are long-lasting issues such as the HIV-AIDS epidemic or the climate crisis, where the critical period lasts for years. In both scenarios, there is no excessive time pressure on researchers. In contrast, during a pandemic, circumstances can change within days and decisions have to be made quickly to take action and prevent further harm. In this regard, a pandemic is similar to events such as volcanic eruptions [Haynes, Barclay and Pidgeon, 2008], oil spills [Lubchenco et al., 2012; McNutt, 2020], and nuclear catastrophes [Shore, 2013], which require immediate intervention, leading to intense time pressure on all involved actors.

\section{Transparency in the context of public attention and confidentiality}

During the COVID-19 pandemic, the researchers "on the frontline" were asked to participate in the publication cycle of broad media outlets to a far greater extent than before the crisis. As a consequence, the CSH's science communication rapidly changed from a "science push" scenario to a "policy (and media) pull" scenario [Bielak et al., 2008; Marcinkowski and Kohring, 2014]. While the CSH continued to publish (push) new results on a webpage dedicated to COVID-19-related research [Complexity Science Hub Vienna, 2020b], direct requests from the media to comment on current developments, as well as direct requests for information from policymakers (pull), sharply increased. There was also a new and intense interest in the scientific process itself, including broad media reporting about preprints and scientific disputes. This phenomenon of mass media reporting on communications that are usually intended only for expert audiences could be witnessed on a global scale; for instance, the discussion in the U.K. of the simulation of case number predictions [Boland and Zolfagharifard, 2020] and a discussion in Germany on the viral load of children [Bild, 2020]. As a result of the increased exposure, the origin of information sources used in our research, such as anonymized mobile phone localization records, was critically questioned by the media, and transparency was demanded. On the other hand, confidentiality for parts of our results and 
information sources was required, for reasons of national security as well as data protection.

\section{Communicating complex information and uncertainty}

The scientific process at the onset of the COVID-19 pandemic was characterised by a high degree of unknowable uncertainty [Chua Chow and Sarin, 2002] in relation to the assessment of risk and future development of the pandemic. This included the biological parameters of the virus and the associated disease as well as the most effective strategy to curb its spread. Due to test shortages, the spread of the virus was also poorly understood. In this context, science had to be communicated while emphasizing the uncertainty involved in the issue [Fischhoff, 2012]. Policymakers needed to be aware of the uncertainties when making hard choices under time pressure [Renn, 2010]. The complexity of the information provided and the uncertainty involved thus made it challenging to satisfy the general demand for practical advice.

We chose the following case studies to exemplify the aforementioned challenges and describe the strategies we used to overcome them.

(I) Predicting case numbers: communication under time pressure
During the onset of the COVID-19 pandemic in Europe in mid-February to early March 2020, it was not entirely clear to which extent the public - but also policymakers - understood the gravity of the situation. Observing the early epidemic growth pattern in Austria for two to three weeks showed that the increase of the number of confirmed cases could be reasonably approximated by exponential growth, as is often observed for uncontrolled outbreaks of infectious diseases [Anderson and May, 1992]. Initially, we observed a doubling time of around 2.3 days. This fact, together with the assumption that any kind of non-pharmaceutical intervention to curb the spread of the disease would have an effect with a time delay of one to two weeks, meant that decisions to implement interventions needed to be taken proactively. While data on infection numbers was publicly available [Austrian Federal Ministry for Health, 2020a] it was not clear how many intensive care beds were available for the treatment of severe and critical COVID patients. To obtain this number, we parsed data from an online resource for hospital bed numbers and their average occupancy from the Ministry of Health [Austrian Federal Ministry for Health, 2020b]. Extrapolating the observed exponential trend and using available estimates for hospitalization probabilities [Wang et al., 2020] allowed for a back-of-the-envelope calculation of the point in time at which the pandemic would overwhelm hospital capacities.

To convey the urgency of the situation, we depicted the projection of hospitalized case numbers based on historic cases on a standard line plot (see Figure 1). By including "thresholds" of available beds, the graph thus also illustrated the capacity of the healthcare system, how much of this capacity remained, and when the thresholds of available hospital beds would be crossed.

Given our assumptions, there were three main sources for uncertainty, namely the (i) observed growth rate, (ii) available beds, and (iii) probability of hospitalization. Under exponential growth, even errors of a factor of two in the case numbers 


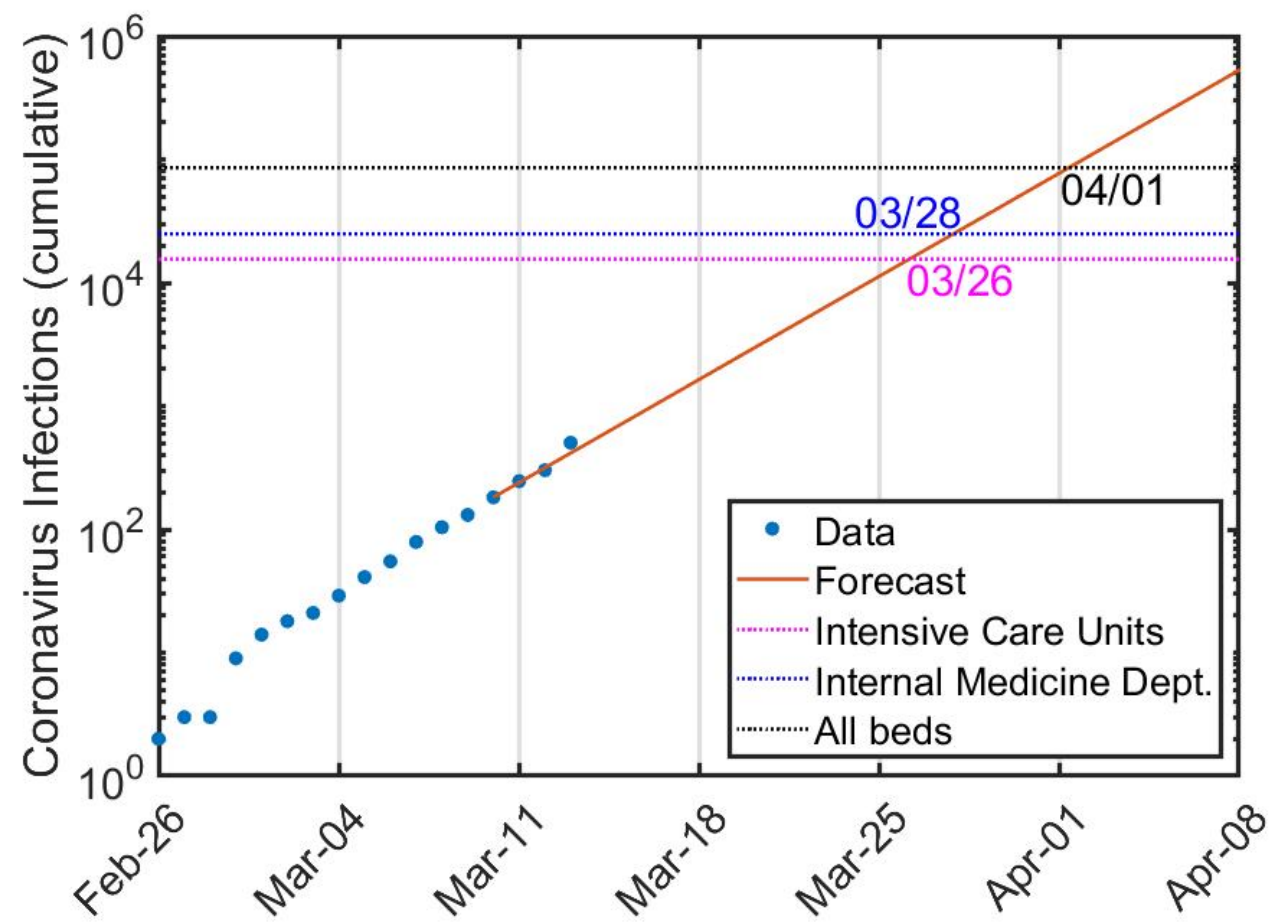

Figure 1. Initial communication about the projection of case numbers and ICU capacity in Austria. The graph shows an estimate of the hospitalized infections based on historic case numbers of the last two weeks at that time (blue dots) and a prediction of hospitalized case numbers for the coming month (brown line). Horizontal dashed lines indicate the number of available hospital beds.

would only slightly shift the day on which the capacity threshold was reached and would not alter our main findings. We therefore decided not to illustrate this uncertainty for the sake of clarity, but we discuss this limitation in the text. What remains is the structural uncertainty concerning the assumption of constant exponential growth. We decided to monitor the growth pattern daily and immediately report deviations from this assumption.

We made this prediction for Austria within about two days, allowing the time to publish a short text and a simple graph (see Figure 1) on Twitter and in a policy brief [Complexity Science Hub Vienna, 2020a] as a press release. We aimed to alert the public to the imminent crisis and urge policymakers to take steps. Good relations with Austrian science desks helped to successfully disseminate our results.

As decision-makers noticed this initial communication, they invited the CSH to participate in an interdisciplinary team of scientists and decision-makers.

Decision-makers expected mid- to long-term (a couple of months) predictions on infection numbers. It took a mutual learning process to help them understand that the expected confidence intervals (i.e., uncertainty) were crucial to showing the limits of this type of prediction of non-linear processes. We were successful in communicating to policymakers that only the "when", not the "if" of our prediction was uncertain: healthcare capacity would be exceeded eventually if no measures were taken and exponential growth of cases of infection continued. An additional 
challenge in this process was that various teams of researchers contributed to predictions at this point, with different approaches to the prediction of case numbers and the estimation of confidence intervals. As a result, policymakers consolidated these approaches to arrive at short-term predictions (over a time horizon of 7-10 days), which were then communicated to the public [Austrian Federal Ministry for Social Affairs, 2020].

The figures, numbers, and predictions about COVID-19 cases in Austria and daily updates on our webpage were disseminated by the media without questioning our results or methods. Nevertheless, we successfully conveyed the uncertainty of our results to media outlets: some outlets communicated the assumptions underlying the prediction (continued exponential growth) [APA, 2020a] while others reported the confidence intervals for the point in time at which hospital capacity would be reached [Österreichischer Rundfunk, 2020a]. All reports communicated that the point in time at which the healthcare capacity would be exceeded was an approximate and not an exact prediction.

Due to the rapid pace of developments and communication at the beginning of the pandemic, scientists, as well as journalists, were in danger of producing inaccurate or not well-founded information. The CSH did not become involved in a controversy about forecasting methods around the end of April, when an unpublished mathematical paper predicted horrendous numbers of possible cases in the near future [Hermisson et al., 2020; Metzger, 2020]. The numbers were used by the Austrian Chancellor in a press conference [Bischof, 2020] that later was labelled as spreading unnecessary panic [Der Standard, 2020b; Österreichischer Rundfunk, 2020c]. This situation highlighted the need for internal quality control before publication, which was amplified by the real danger of causing panic when disseminating results in a misleading way.

(II) Measure effectiveness: between transparency and data protection
To curb the spread of the virus and slow down the exponential growth in the number of infections that was showcased in the first case study, the Austrian government implemented countermeasures. An extensive lockdown was imposed, starting on 16 March, allowing only four reasons to leave the house: work, if not suspensible, shopping for food and other essential goods, assisting people in need, and taking short walks. Subsequently, decision-makers were interested in the level of adherence to the lockdown rules to determine whether even stricter measures, as imposed e.g. in Spain or northern Italy, would be necessary.

To answer this question, we measured the reduction of population movement (radius of gyration [Gauvin et al., 2020]) based on mobile phone localization data [Heiler and Reisch, 2020c; Heiler and Reisch, 2020a; Heiler and Reisch, 2020b; Heiler, Reisch et al., 2020] (see Figure 2) and the reduction of the number of passengers passing through metro stations in Vienna (see Figure 3). The emphasis was on showcasing the dramatic change in mobility and on quantifying said reduction. An additional aim of our communication was to share information about the change in movement patterns with the public, which was previously provided only to the government by other parties [Bechtold, Prenner and Dax, 2020]. We continued to update the plots regularly throughout the pandemic, especially monitoring the changes around Easter and 1 May, when the first easing of the 


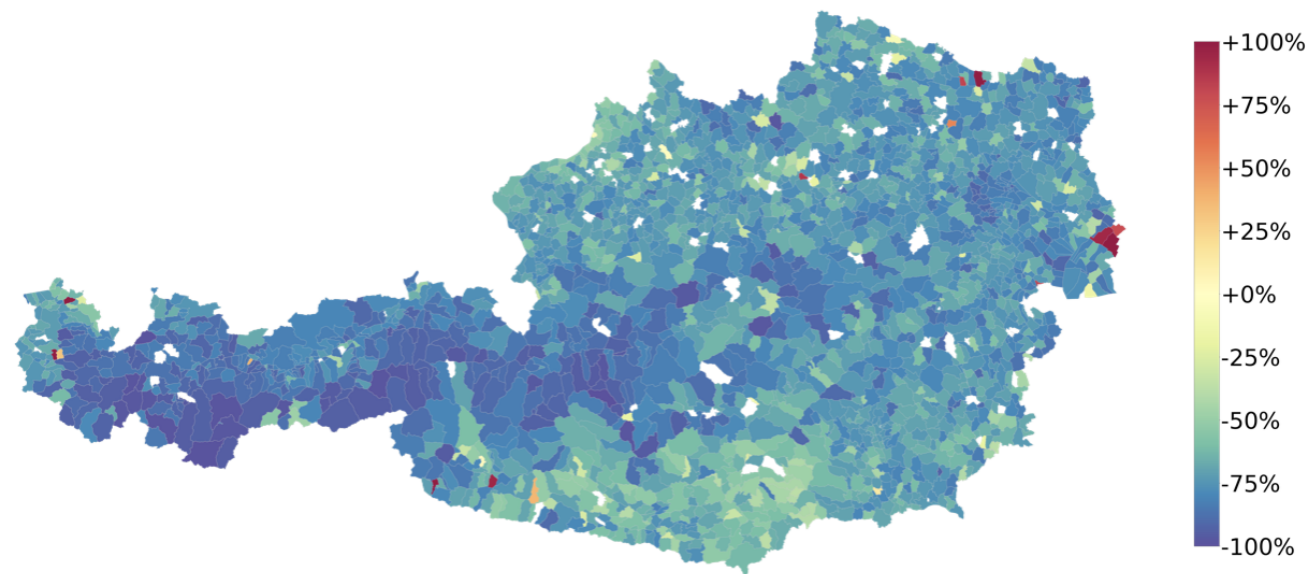

Figure 2. Relative difference in movement range between March 2nd and March 16th.

lockdown measures took place. By now, similar data about movement patterns is publicly available for many different countries [Apple, 2020; Google, 2020].

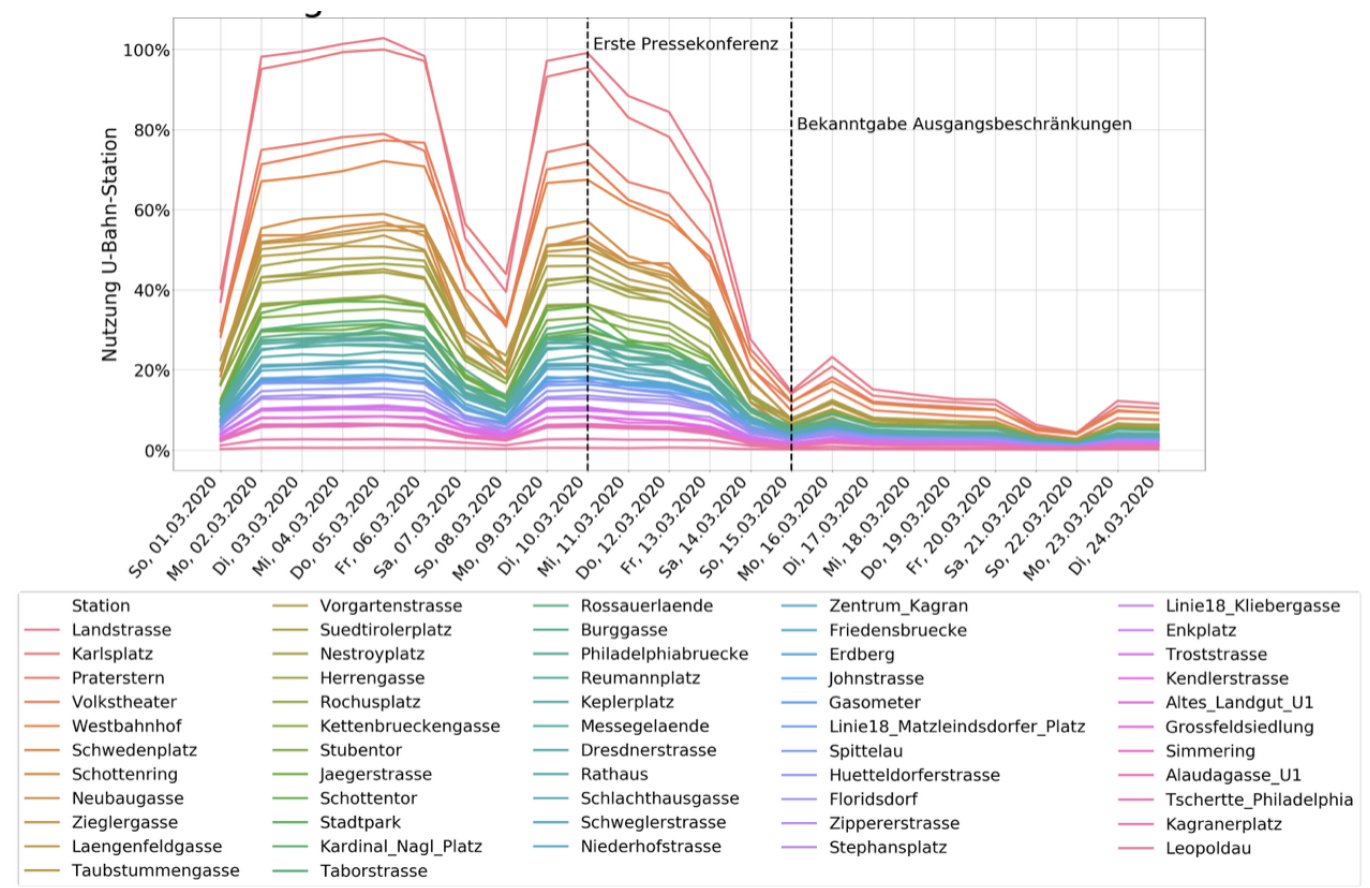

Figure 3. Relative load of passengers in the Vienna subway, listed per stop, over time between March 1st and March 24th.

In the first days, the CSH missed the opportunity to communicate clearly that it was never in possession of the raw mobile phone localization data and analysed only aggregates. This became an issue when an Austrian media outlet asked for data access to create its own visualizations. When we declared that we could not provide data (instead of stating that we did not have it), the media outlet commented negatively on the refusal, claiming that the CSH would do "movement data analyses" "for the federal government" only, but would not share this information with the public [Addendum, 2020]. 
The visualizations published by the CSH quantify how mobility has decreased as an effect of the lockdown, in terms of when (the temporal development), where (geographic variability), and how much of the population adhered to the imposed restrictions. When restricted to static/non-interactive images, there is a tradeoff as to which parts of this information to convey. In Figure 2, information is temporally aggregated to show the relative difference between movement ranges between two calendar weeks in the map's colour channel. Figure 3 displays the relative change in the passenger load in the Vienna subway system over time. Subway stops (inherently spatial information) are thereby abstracted to individual lines in the plot.

(III) "Corona Traffic Light": the complexity of simple communication
From the perspective of healthcare professionals and policymakers, a timely and regional epidemiological risk assessment tool was essential for an appropriate response during the ongoing pandemic. Depending on the regional severity and underlying trends, primary care organizations adopted different modes of risk management. Many public dashboards showing the global spread of the infection at the time (see for example [John Hopkins University, 2020] ) only conveyed absolute case numbers, while not taking other healthcare-related aspects, such as the availability of doctors in a region, into account. To accurately judge the severity of the situation across regions, knowledge about relative regional case numbers was required. To satisfy this requirement, in mid-April, we developed the "Corona Traffic Light" as a visual tool for risk communication, which we published on our webpage for Austria and the world [Sprenger et al., 2020b; Sprenger et al., 2020a]. It allows the current regional epidemiological situation in Austria to be communicated to healthcare professionals, policymakers, and the general public, facilitating the establishment of local measures.

We used a commonly understood visual metaphor, i.e. the "traffic light" system with three colours, to make the visualization easier to grasp [Ziemkiewicz and Kosara, 2008]. We chose the number of SARS-CoV-2-positive tested cases in the last 14 days (conforming to one incubation period [Lauer et al., 2020] ) per 10,000 citizens as the unit of measurement for describing the regional situation. A green region conveys that normal life, without (severe) restrictions, is possible. On the other end of the spectrum, the colour red conveys a high regional infection risk. Cut-off values between the three levels needed to be chosen carefully to avoid creating a false sense of safety if a region was coloured green, or panic if a region turned yellow. Based on the feedback of healthcare practitioners, we defined the cut-off value for the red level as more than 10 SARS-CoV-2 positive tested cases in the last 14 days per 10,000 citizens. In such regions, severe measures are mandated to reduce the reproduction number of the virus. A region is yellow if there are between one and ten positively tested persons per 10,000 citizens. In these areas, measures should be taken according to the trend of the infection rate, that is, light or severe measures when the rate is decreasing or increasing, respectively. The trend of the regional temporal development can be queried interactively by the user (see Figure $4 \mathrm{~d}$ ).

While the thresholds for the traffic light colours were curated by healthcare experts, the tool did not explicitly answer questions such as "How safe is a green zone?", "How dangerous is a red zone?", or "Which kind of countermeasures are appropriate/necessary for each colour?" Such guidelines needed to be developed by healthcare professionals and policymakers, such that the "Corona Traffic Light" 


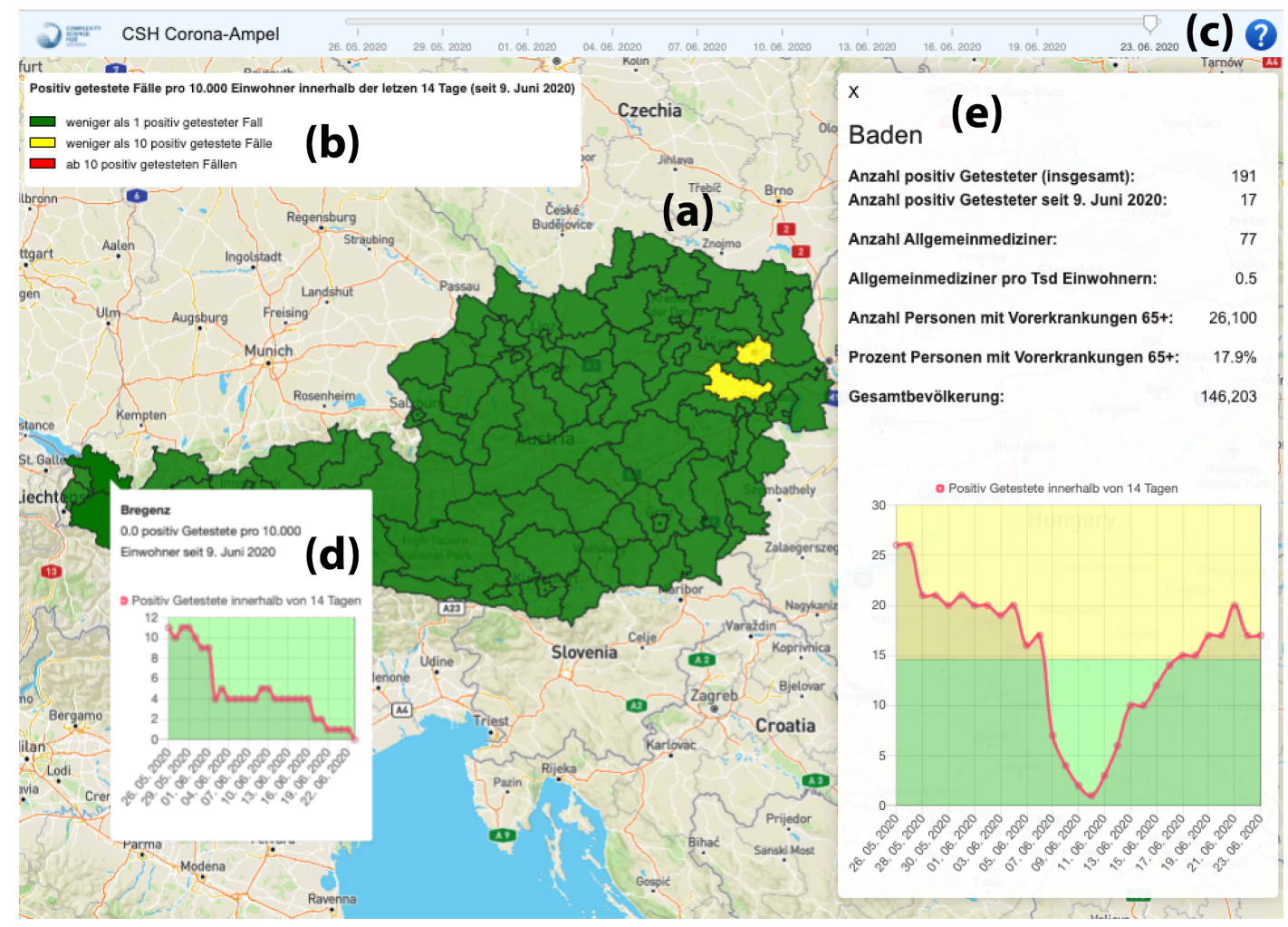

Figure 4. Overview of the Corna Traffic Light interface. (a) The map is displayed on the resolution of political districts, colored according to the current risk-level. Levels are described on a legend (b): green = less than one positively tested person across 10.000 citizens, yellow $=$ less than ten positively tested, red $=$ more than ten. The time-slider (c) enables a historic perspective of the situation within the last 30 days. By hovering on a district with the mousepointer, the local trend of the pandemic can be assessed (d). Additional regional information, such as the number of citizens in risk groups, can be accessed by clicking on a district (e).

can be used as a basis for decisions on the implementation of measures during possible recurring waves of infections.

We featured the Corona Traffic Light on the CSH webpage and through a press release, social media, and personal contacts to journalists. Its catchy name likely helped in the dissemination process: it was immediately picked up by the mass media and became the most used tool on the $\mathrm{CSH}$ webpage, and click rates remained high despite decreasing infection numbers.

Healthcare professionals reacted very positively to the visualization. Some health centres started to develop status reports for their patients based on the tool, which were placed prominently in the entrance area. Similar to a weather forecast, they informed patients about the current regional and nationwide situation and the necessary regional preventive measures regarding hygiene, patient management and usage of protective equipment.

A chapter of the Austrian Economic Chambers considered using the tool to decide which borders to neighbouring countries could be opened. Between green regions, there was no reason to restrict travel. However, for this to work, the tool would have to be coordinated and curated on a European scale. In addition, not all policymakers were enthusiastic about the Corona Traffic Light. Some raised 
concerns that it "punished" regions that were testing the most, as these regions would detect more cases and appear less secure as a consequence. This was an unintended consequence of our tool.

Similar traffic-light-inspired tools for risk assessment have also surfaced in other countries [Berlin.de, 2020; risklayer, 2020]. While such tools can be purely descriptive, i.e. without assigning specific risk levels to thresholds [risklayer, 2020], the Senate of Berlin used the traffic-light system to determine the necessity of countermeasures [Berlin.de, 2020]. However, the reaction and critique from the media and the public [rbb24, 2020], including attempts to reverse-engineer the Senate's metrics due to a lack of transparency, illustrate the importance of clear communication regarding data sources and the calculation of risk factors. In July 2020, the Austrian government announced a government-regulated Corona Traffic Light for risk management during a potential second wave in autumn [APA, 2020b; Gaigg and Müller, 2020].

(IV) Social media and emotions: between nuanced scientific approaches and practical advice
As the countermeasures implemented constituted an immense interference into the living conditions and fundamental rights of the Austrian population, researchers at the CSH quickly became interested in assessing the sentiment of the population. In the early weeks of the SARS-CoV-2 outbreak, we published several reports about the evolution of emotional and social expressions on Twitter in 2020 in different countries, including Austria (see Figure 5) [Metzler, Rimé and Garcia, 2020]. Next, we built an online emotion monitor that was automatically updated daily [Pellert et al., 2020] based on text data from Twitter, the online discussion forum of a major Austrian newspaper, and a chat platform for young adults. In the initial reports on the $\mathrm{CSH}$ website, we focused on increases in expressions of anxiety (the most relevant collective emotion in response to a threat) and prosocial attitudes (a positive aspect of the public response). In these reports, we also included recommendations for psychological health and links to reliable information sources about SARS-CoV2. We further investigated changes in anger, sadness, positive emotions, and social terms such as "family" or "help", and presented these results via the online monitor, interviews with journalists, and presentations to policymakers.

The most difficult tradeoff in visualizing emotion timelines concerned the advantages and disadvantages of showing absolute compared to relative percentage values of emotional expressions. Showing absolute values, on the one hand, helps to accurately interpret the extent of a change in relation to the base rate, but does not allow comparison between different countries and languages, which readers intuitively make nonetheless. Relative percentages, on the other hand, account for irrelevant differences in the baseline levels and thus allow comparisons, but easily lead to overestimating the importance of a change if the base rate is low. Eventually, we chose relative percentages to prevent misinterpretations of differences in baselines that depended only on small differences in the emotion measures for different languages. To allow readers to interactively explore the figures in the online reports and monitor (zoom, look at specific dates or values), we compiled figures with the R package Plotly [Plotly Technologies Inc., 2015].

We sent a short description of our social media analysis to all CSH press contacts, informed the Austrian Press Agency (science desk) in a personal telephone call, 


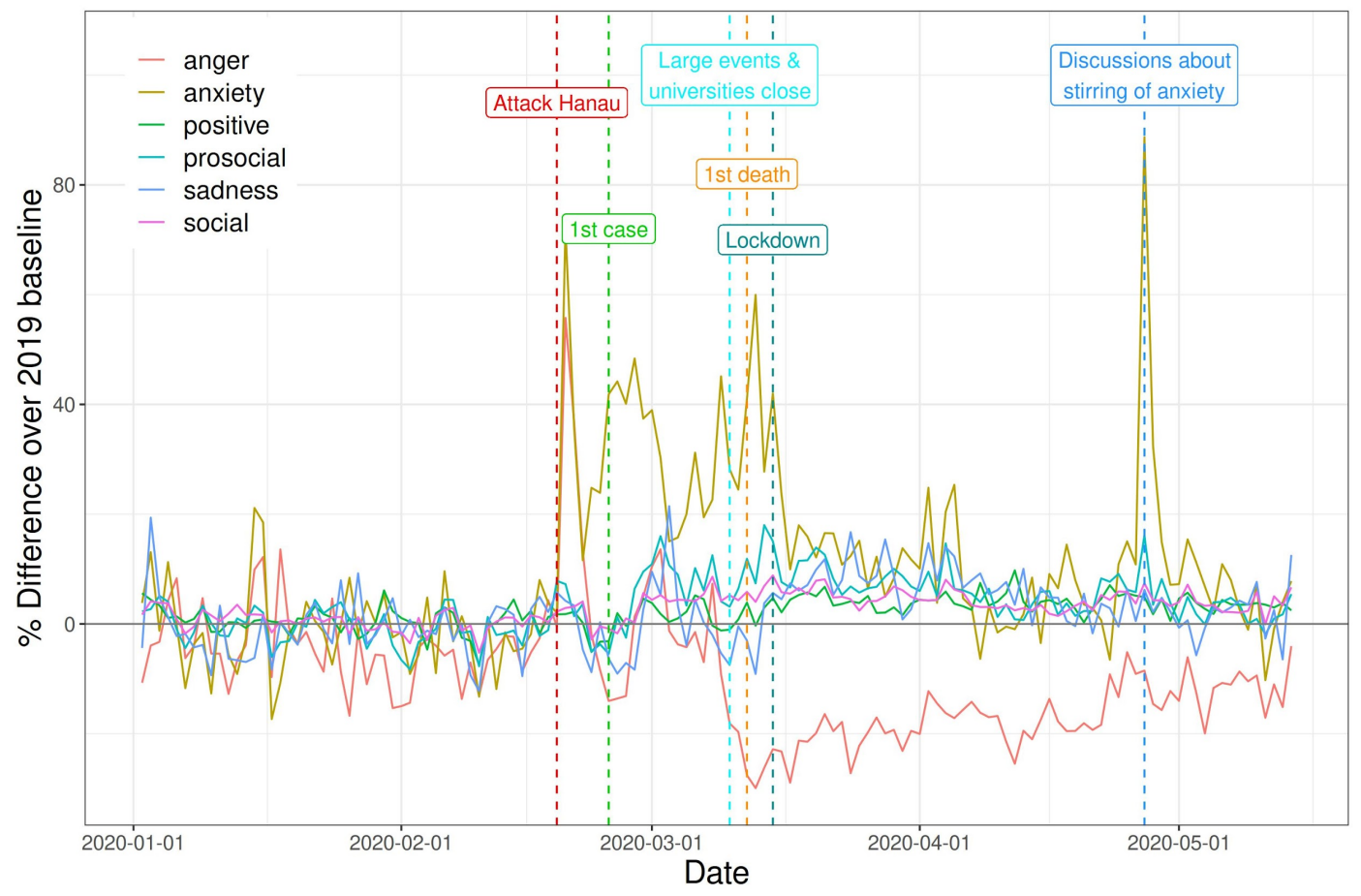

Figure 5. Changes in the percentage of tweets containing at least one emotional or social term on Twitter compared to the baseline in Austria. A value of zero corresponds to the average level per weekday in 2019 (baseline). We believe that the marked decline in anger during the time of lockdown in Austria is caused by the reduction of words referring to violent incidents, such as robberies or demonstrations and the shift of public discourse towards corona related topics [Pellert et al., 2020]. This is also supported by reports of drastically decreased criminality in Austria during the lockdown [Weichhart, 2020].

and shared some results via Twitter and Facebook. We did not publish these reports for a specific purpose other than allowing the public to reflect on their own emotional experiences. Nevertheless, they quickly caught the attention of policymakers looking for advice regarding measures against the outbreak. Participating in the COVID-19 Future Operations Clearing Board (an interdisciplinary platform for exchange between researchers and politicians initiated by the Austrian Federal Chancellery), we realized that social media analyses may satisfy policymakers' need for up-to-date results, but cannot provide direct recommendations for political decisions. As politicians focused on recommendations and direct answers to questions about the degree of acceptance or psychological consequences of measures, we realized the importance of communicating the limited conclusions that a particular analysis allows.

Our results were featured by the Austrian Press Agency, and consequently in several online newspapers, including Der Standard, Science.ORF.at, and Wiener Zeitung [Der Standard, 2020a; Österreichischer Rundfunk, 2020b; Wiener Zeitung Online, 2020]. Early reports by science journalists demonstrated that we had successfully communicated a nuanced interpretation of our results, including potential misunderstandings. Later media requests were mostly interested in people's opinions about the measures, exciting novel results or results that confirmed journalists' expectations. We insisted on cautious interpretations and 
actual empirical evidence by emphasizing, for instance, that our results capture only emotional expressions, not emotions themselves, or by clarifying that expressions of anger remained below the baseline for three months in a row after the onset of the pandemic, despite increasing criticism of measures in the media. As a result, these later interviews (e.g. with Puls 4, Die Presse, Focus) were never published. This highlights a real tradeoff between capturing the attention of the media and the public and achieving an accurate and nuanced presentation of scientific results.

Lessons learned from communicating science in times of crisis
In the following, we discuss strategies on how to deal with the three challenges that we defined in the course of this paper: time pressure, transparency, and communicating complex information, and that were illustrated in our case studies. A brief summary of the insights described in this article in the form of practical guidelines can be found as a supplementary text.

\section{Dealing with time pressure}

One way to tackle the increased time pressure of the short cycles between receiving, evaluating, and presenting insights gained from new information is to break down scientific questions and results into smaller units, or to establish continuous reporting outlets in the form of monitors. This strategy is especially feasible when monitoring and communicating daily changes, such as case numbers [Sprenger et al., 2020b], movement patterns [Complexity Science Hub Vienna, 2020b] and population sentiment [Pellert et al., 2020] to inform decision-makers and the public in real time.

In these cases, communication and dissemination are facilitated and become more effective, i.e. better received and understood, if message content and format adhere to common standards [Ziemkiewicz and Kosara, 2008]. Governmental agencies such as the CDC in the U.S.A. have developed crisis-communication strategies for catastrophic events [Dalrymple, Young and Tully, 2016; Reynolds and Quinn, 2008; Reynolds and Seeger, 2005]. Like these agencies, research institutions should become aware of the potential impact of their area of expertise in times of crisis and develop crisis-communication strategies accordingly. They should be prepared to quickly transition from a "science push" to a "policy pull" [Bielak et al., 2008] mode of communication in times of crisis and have a clear plan for communication responsibilities and workflow. Implementing such a plan also has the potential to lower the time spent on coordinating the communication. The plan should also include the legal aspects of handling sensitive data such as patient health records or mobile phone data. Clarifying these aspects during a crisis takes significant amounts of time and severely hampers communication.

Next to a "crisis strategy", another remedy to produce correct results with fewer means for quality control is to involve as many colleagues as possible in the scientific and modelling process to mimic an informal "review process" under stress. A necessary means for this is more efficient internal communication. During "corona-mode" at the CSH, the use of a central communication platform (Slack) was enforced, which facilitated sharing and discussing information in an internally transparent way. At the same time, daily group calls offered the possibility to ask 
peers for internal review and proofreading of results and methods and to spot the potential for misunderstandings of the communication.

Such quality checks could also be made transparent to decision-makers and the public to foster trust. Nevertheless, the reduced time for debate most certainly results in lower-quality output, and the risk that scientists lose their most valuable good reputation - is high. By employing the highest standards of transparency and proactive communication of uncertainties, this risk can be minimized to some extent.

\section{Managing transparency}

Throughout the COVID-19 pandemic, we perceived an increased interest of the public in the scientific process. The crisis has shown that transparency of the scientific process is increasingly being demanded by the public and is needed to quickly share and discuss results and methods among experts and policymakers. Communicating the entire scientific process, including the context as well as the methods and data used for research, is becoming increasingly important in communication to non-experts as well.

Surveys conducted during the crisis show a sharp increase of trust in science and scientists [Carrell, 2020; Wissenschaft im Dialog, 2020], which also results in acceptance and adoption of protective measures [Dohle, Wingen and Schreiber, 2020]. This is in line with previous reports of the perception of scientists as a trustworthy source of information during a crisis [Haynes, Barclay and Pidgeon, 2008]. Therefore, next to the challenges, the COVID-19 pandemic also offers the unique opportunity to strengthen the role of science in public discussions and future policy decisions through proactive and transparent communication and to inform the public about the scientific process.

However, if results are still in the making, if solid conclusions are not yet possible, or if the refereeing process is not yet completed, the question of how scientists should communicate transparently remains open. Should scientists discuss their doubts openly in public - risking stress from public exposure - or should they involve only decision-makers in the discussion?

For the COVID-19 pandemic, there is evidence that the presence of corrective information helps to debunk misinformation [van der Meer and Jin, 2020] and to increase compliance with measures [Hameleers, van der Meer and Brosius, 2020]. This indicates that the public should be transparently informed about the current state of affairs and be involved in the ongoing discussion of policy decisions, and can be trusted to act cooperatively and intelligently. Still, both approaches - complete transparency and holding back results until they have been subject to rigorous quality checks - are valid in certain circumstances and need to be balanced in crisis communication.

To strike this balance in practice, we established an internal review system to ensure results were checked by several researchers before they were communicated to the public. Additionally, we aimed to publish the data, methods and source code underlying our results wherever legally possible. 
In the current COVID-19 pandemic, both policymakers and scientists had access to the relevant information and engaged in communication with the public. In our experience, policymakers tend to resort to streamlined communication that emphasizes confidentiality and is designed to persuade the population to comply with measures. This leaves the role of the "transparency creators" to the scientists, who must balance the political communication in times of crisis. While this comes with a high additional time cost and a potential risk to reputation, we think it is the responsibility of scientists to take this role and to proactively publish the maximum possible amount of information to create transparency wherever legally possible as we did with our analysis of movement patterns during the crisis.

In the context of Open Science, publishing preliminary results in the form of preprints, data and methods has gained considerable traction in the scientific community during the last years in the interests of fostering research reproducibility and integrity [Fidler and Wilcox, 2018; Munafò, 2016]. During times of crisis, Open Science practices create transparency and can help improve trust. To this end, adopting Open Science workflows in everyday scientific work facilitates transparent communication in times of crisis and lowers the additional strain on limited time resources incurred by getting used to new practices during times of crisis. Here, an important aspect is also a clear description of the exact nature and source of data sets that are used - especially when sensible data sets are analysed. To this end, we included extensive information about data sources and data processing in the disclaimers accompanying both the Corona Traffic Light and the emotion monitor.

\section{Communicating complex information}

When communicating scientific results or processes, the message has to be tailored to the target audience - this holds true for visual as well as verbal communication. This curation of a message concerns not only the degree of detail and complexity conveyed, but also the tone of the message.

Extreme and careless reporting has the potential to incite fear and can be used by the tabloid press to create the impression of chaos and incompetence [Bild, 2020], which no scientist wants to be associated with. This also places additional strain on the researcher's time to clarify misunderstandings and debunk false results. Still, the hypothesis of "disaster panic", which assumes that in emergencies people will give in to mass hysteria, has been disproven by disaster experts in the last decades [Gantt and Gantt, 2012; Auf der Heide, 2004; Sandman and Lanard, 2005]. Historical evidence also points to groundswells of organized and prosocial behaviour during and after disasters [Bernardini and Hart, 2011; Fritz and Williams, 1957; Grimm et al., 2014; Zaki, 2020]. This strengthens our conviction to be transparent and trust the public with information, even if it is uncomfortable. Nevertheless, researchers should never compromise on the communication of uncertainty - even when the demand for simple answers and clear advice is high, as was the case for the prediction of case numbers and the monitoring of public sentiment.

While visual communication can help to foster the dissemination of research results in a way that is easy to understand intuitively, careless design decisions can have 
the opposite effect. If counter-intuitive encodings are chosen or if the information is presented in a way that is too complex for the target audience to grasp, results can be misinterpreted. It is therefore important to double-check whether the intended message was received, which is challenging under time pressure. In the case of the emotion monitor, we tried to predict possible sources of misunderstanding by the users beforehand and carefully chose the visualizations accordingly. The Corona Traffic Light was shown to several healthcare practitioners to aid with streamlining metrics and representation before going public.

Another aspect to consider is the tradeoff between the simplicity of a message and its completeness. An oversimplified presentation could be prone to false interpretation due to missing information, while a presentation overloaded with details can be overwhelming even for expert audiences. In the case of the Corona Traffic Light, the colours send a clear message thanks to the familiar metaphor. However, the way the data was aggregated was confusing for some users. The temporal aggregation over two weeks was perceived as arbitrary by some, although it was based on the maximal incubation period of the virus. The use of fractions (one case per 10,000 inhabitants) was confusing when representing less than one inhabitant. This shows how important it is to keep the information simple if it is targeted at a broader public. Conversely, simplification always poses the risk of omitting relevant information: the omission of testing rates in a region allowed for misinterpretation of infection risk based solely on infection numbers.

The tradeoff between simplicity and completeness can also be remedied by giving users dynamic control over the visualization if it is hosted in an interactive format - as was the case for the Corona Traffic Light and the emotion monitor. Interactive elements can include, for example, different threshold specifications, or changing the temporal aggregation window and the information included in the display.

Another challenge is the visual communication of uncertainty, which can make an already complex message less clear and less understandable. "As little as possible, as much as necessary" [Ware, 2019] is the guideline here, but it is not always straightforward to follow. Another way to deal with this tradeoff is to provide multiple static representations, conveying the same topic with increasing complexity. Similar to an interactive website representation, interested audiences thus can delve deeper into a topic, to a level that matches their interest and/or expertise.

Trust and transparency can also be an issue in visual communication, even if a visualization conveys only raw data (where does the data come from?), but especially when the displayed results stem from data transformations (how were the results calculated?). In such cases, it is essential to reference sources and methods in accordance with the Open Science spirit. This is why we included extensive disclaimers in our reporting of movement patterns and public sentiment and the Corona Traffic Light.

The research-related aspects of the COVID-19 pandemic illustrated in our case studies (case number prediction, assessment of measure effectiveness, visualization of infection risk and investigation of public sentiment) are not specific to Austria, as similar research efforts are currently being undertaken in many countries around 
the world. Therefore, while the case studies presented in this publication are, in their concrete application, specific to Austria, we believe that the insights into science communication during a time of crisis can be generalized to other countries and settings. To this end, we have compiled a short practical guide [Lasser, 2020] based on what we have learned as well as a compilation of all relevant references and online resources pertaining to the four case studies (see supplemental material), in the hope that it can facilitate the preparedness of other research institutions for a crisis.

Acknowledgments This work is supported by the Wiener Wissenschafts-, Forschungs- und Technologie Fonds projects \#COV20-017 "Tagesaktuelle Coronalagekarte" and \#MA16-045, the Vienna Science and Technology Fund project \#VRG16-005, and the Österreichische Forschungsförderungsgesellschaft project \#873927 and FWF project \#P29032 .

We thank Wolfgang Knecht and Martin Knecht for their work on the Corona Traffic Light, and Max Pellert and David Garcia for setting up the Online Emotion Monitor, and Jenny Reddish for language editing of the manuscript.

\section{References}

Addendum (17th April 2020). 'Standortdaten: Wo das öffentliche Leben zurückkehrt'. Addendum. URL: https://www. addendum.org/coronavirus/stand ortdaten-social-distancing/ (visited on 23rd June 2020).

Anderson, R. M. and May, R. M. (1992). Infectious diseases of humans: dynamics and control. Oxford, U.K. and New York, NY, U.S.A.: Oxford University Press.

APA (12th March 2020a). 'Forscher rechnen mit Engpass an Spitalsbetten Anfang April'. Die Presse. URL: https://www . diepresse.com/5783559/forscher-rechn en-mit-engpass-an-spitalsbetten-anfang-april.

- (29th July 2020b). 'Probebetrieb für Corona-Ampelsystem startet Mitte August'. Die Presse. URL: https://www .diepresse.com/5845928/probebetrieb-fur-cor ona-ampelsystem-startet-mitte-august.

Apple (2020). COVID-19 - mobility trends.

URL: https: // covid19. apple.com/mobility (visited on 13th August 2020).

Auf der Heide, E. (2004). 'Common misconceptions about disasters: panic, the 'disaster syndrome' and looting'. In: The first 72 hours: a community approach to disaster preparedness, pp. 340-381. URL: https://www.atsdr.cdc.gov/emerg ency_response/common_misconceptions.pdf.

Austrian Federal Ministry for Health (2020a). Amtliches Dashboard COVID-19. URL: https://info.gesundheitsministerium. at/ (visited on 17th June 2020).

- (2020b). Klinksuche. URL: https: //kliniksuche at/ (visited on 17th June 2020).

Austrian Federal Ministry for Social Affairs (2020). COVID-Prognose-Konsortium. URL: https : //web.archive.org/web/20200819140203/https ://www.sozialmi nisterium. at/Informationen-zum-Coronavirus/COVID-Prognose-Konsortiu m. html (visited on 18th June 2020).

Bechtold, F., Prenner, T. and Dax, P. (17th March 2020). 'Ausgangsbeschränkung: A1 liefert Bewegungsdaten an Regierung'. futurezone.

URL: https: //futurezone . at/netzpolitik/ausgangsbeschraenkung-a1-lief ert-bewegungsprofile-an-regierung/400783565 (visited on 23rd June 2020).

Berlin.de (21st June 2020). 'Corona-Ampel: Die aktuellen Indikatoren'. Berlin.de. URL: https : //www . berlin.de/sen/gpg/service/presse/2020/pressemitteil ung. 948468.php (visited on 23rd June 2020). 
Bernardini, S. and Hart, D. (2011). 'A paradise built in hell: the extraordinary communities that arise in disaster'. Journal of Moral Education 40 (1), pp. 123-125. https://doi.org/10.1080/03057240.2011.541774.

Bielak, A. T., Campbell, A., Pope, S., Schaefer, K. and Shaxson, L. (2008). 'From science communication to knowledge brokering: the shift from 'science push' to 'policy pull". In: Communicating science in social contexts. Ed. by D. Cheng, M. Claessens, T. Gascoigne, J. Metcalfe, B. Schiele and S. Shi. Dordrecht, The Netherlands: Springer, pp. 201-226. https://doi.org/10.1007/978-1-4020-8598-7_12.

Bild (27th May 2020). 'Kritik an Star-Virologe Drosten: “Wir empfehlen, die Studie zurückzuziehen"'. Bild.de. URL: https://www.bild.de/politik/inland/politi $\mathrm{k}$-inland/kritik-an-star-virologe-drosten-wir-empfehlen-die-studie-z urueckzuziehen-70884902.bild.html.

Bischof, D. (30th March 2020). 'Kurz: 'Die Ruhe vor dem Sturm'. Wiener Zeitung. URL: https://www . wienerzeitung.at/nachrichten/politik/oesterreich/20 55993-Regierung-zieht-Corona-Bilanz.html.

Boland, H. and Zolfagharifard, E. (16th May 2020). 'Coding that led to lockdown was 'totally unreliable' and a 'buggy mess', say experts'. The Telegraph.

URL: https://www . telegraph . co.uk/technology/2020/05/16/coding-led-lo ckdown-totally-unreliable-buggy-mess-say-experts/.

Carrell, S. (5th May 2020). 'Trust in scientists grows as fake coronavirus news rises, U.K. poll finds'. The Guardian.

URL: https://www . theguardian.com/world/2020/may/05/trust-in-scientis ts-grows-as-fake-coronavirus-news-rises-uk-poll-finds (visited on 17th June 2020).

Chua Chow, C. and Sarin, R. K. (2002). 'Known, unknown and unknowable uncertainties'. Theory and Decision 52 (2), pp. 127-138. https://doi.org/10.1023/A:1015544715608.

Complexity Science Hub Vienna (14th March 2020a). Coronavirus: Kapazitäten bei Spitalsbetten - CSH. URL: https://www.csh.ac.at/csh-policy-brief-corona virus-kapazitaetsengpaesse-spitalsbetten/ (visited on 12th June 2020).

- (2020b). CSH COVID-19 Info Point. URL: https ://csh.ac.at/covid19/ (visited on 17th June 2020).

Dalrymple, K. E., Young, R. and Tully, M. (2016). "Facts, not fear": negotiating uncertainty on social media during the 2014 Ebola crisis'. Science Communication 38 (4), pp. 442-467. https : //doi .org/10.1177/1075547016655546.

Der Standard (20th March 2020a). ‘Coronavirus: Twitter spiegelt Ängste und Sorgen der Menschen wider'. Der Standard.

URL: https://www . derstandard.at/story/2000115973796/coronavirus-twit ter-spiegelt-aengste-und-sorgen-der-menschen-wider (visited on 9th June 2020).

- (27th April 2020b). 'Sitzungsprotokoll der 'Taskforce Corona' über zu wenig Angst in der Bevölkerung'. Der Standard.

URL: https://www.derstandard.at/story/2000117131591/sitzungsprotokol l-der-taskforce-corona-ueber-zu-wenig-angst-in-der (visited on 9th June 2020).

Dohle, S., Wingen, T. and Schreiber, M. (2020). 'Acceptance and adoption of protective measures during the COVID-19 pandemic: the role of trust in politics and trust in science'. Preprint in Open Science Framework.

https://doi.org/10.31219/osf.io/w52nv. 
Fidler, F. and Wilcox, J. (2018). 'Reproducibility of scientific results'. In: The Stanford Encyclopedia of Philosophy (Winter 2018). Ed. by E. N. Zalta.

URL: https://plato. stanford.edu/archives/win2018/entries/scientificreproducibility/.

Fischhoff, B. (2012). 'Communicating uncertainty: fulfilling the duty to inform'. Issues in Science and Technology 28 (4). URL: https: //issues . org/fischhoff / (visited on 17th June 2020).

Fritz, C. E. and Williams, H. B. (1957). 'The human being in disasters: a research perspective'. The ANNALS of the American Academy of Political and Social Science 309 (1), pp. 42-51. https: //doi .org/10.1177/000271625730900107.

Gaigg, V. and Müller, W. (7th August 2020). 'Risikoabwägung im Sommer und Herbst durch Corona-Ampel und Reisewarnungen'. Der Standard.

URL: https://www . derstandard.at/story/2000119222309/risikoabwaegungim-sommer-und-im-herbst-durch-corona-ampel-und.

Gantt, P. and Gantt, R. (2012). 'Disaster psychology: dispelling the myths of panic'. Professional Safety 57 (8), pp. 42-49.

Gauvin, L., Tizzoni, M., Piaggesi, S., Young, A., Adler, N., Verhulst, S., Ferres, L. and Cattuto, C. (2020). 'Gender gaps in urban mobility'. Humanities and Social Sciences Communications 7 (1). https://doi .org/10.1057/s41599-020-0500-x.

Google (2020). COVID-19 community mobility report.

URL: https://www.google.com/COVID19/mobility?hl=de (visited on 13th August 2020).

Grimm, A., Hulse, L., Preiss, M. and Schmidt, S. (2014). 'Behavioural, emotional and cognitive responses in European disasters: results of survivor interviews'. Disasters 38 (1), pp. 62-83. https: //doi .org/10.1111/disa.12034.

Hameleers, M., van der Meer, T. G. L. A. and Brosius, A. (31st May 2020). 'Feeling "disinformed" lowers compliance with COVID-19 guidelines: evidence from the U.S., U.K., Netherlands and Germany'. Harvard Kennedy School Misinformation Review. https://doi .org/10.37016/mr-2020-023.

Haynes, K., Barclay, J. and Pidgeon, N. (2008). 'The issue of trust and its influence on risk communication during a volcanic crisis'. Bulletin of Volcanology 70 (5), pp. 605-621. https://doi .org/10.1007/s00445-007-0156-z.

Heiler, G. and Reisch, T. (30th April 2020a). Corona - How measures work [April] — CSH. URL: https://www. csh.ac . at/coronavirus-how-measures-work-wirksa mkeit-der-massnahmen-oesterreich-april/ (visited on 24th August 2020).

- (15th May 2020b). Corona - How measures work [May] - CSH.

URL: https://www.csh.ac . at/coronavirus-how-measures-work-wirksamkeit -der-massnahmen-oesterreich-may/ (visited on 24th August 2020).

- (1st January 2020c). Corona - Wirksamkeit der Massnahmen [März] - CSH. URL: https://www.csh.ac.at/coronavirus-wirksamkeit-der-massnahmen-in - oesterreich/ (visited on 24th August 2020).

Heiler, G., Reisch, T., Hurt, J., Forghani, M., Omani, A., Hanbury, A. and Karimipour, F. (2020). 'Country-wide mobility changes observed using mobile phone data during COVID-19 pandemic'. arXiv: 2008.10064.

Hermisson, J., Nordborg, M., Grohs, P. and Schachermayer, W. (29th April 2020). 'Über Modelle, Prognosen und die Realität von COVID-19'. Falter. URL: https://www .falter .at/zeitung/20200429/ueber-modelle-prognosenund-die-realitaet-von-COVID- 19.

John Hopkins University (2020). COVID-19 map. Johns Hopkins Coronavirus Resource Center. URL: https: //coronavirus. jhu. edu/map.html (visited on 22nd June 2020). 
Lasser, J. (2020). 'A practical guide for the organization of science communication of a research institution during a crisis'. https://doi.org/10.17605/OSF. IO/UG4FK.

Lauer, S. A., Grantz, K. H., Bi, Q., Jones, F. K., Zheng, Q., Meredith, H. R., Azman, A. S., Reich, N. G. and Lessler, J. (2020). 'The incubation period of coronavirus disease 2019 (COVID-19) from publicly reported confirmed cases: estimation and application'. Annals of Internal Medicine 172 (9), pp. 577-582. https://doi.org/10.7326/m20-0504.

Lubchenco, J., McNutt, M. K., Dreyfus, G., Murawski, S. A., Kennedy, D. M., Anastas, P. T., Chu, S. and Hunter, T. (2012). 'Science in support of the Deepwater Horizon response'. Proceedings of the National Academy of Sciences 109 (50), pp. 20212-20221. https://doi .org/10.1073/pnas. 1204729109.

Marcinkowski, F. and Kohring, M. (2014). 'The changing rationale of science communication: a challenge to scientific autonomy'. JCOM 13 (03), C01. URL: http://jcom.sissa.it/archive/13/03/JCOM_1303_2014_C01.

McNutt, M. (16th June 2020). 'Delivering science in a crisis'. Issues in Science and Technology. URL: https://issues .org/mcnutt-actionable-strategic-irrepl aceable-data-delivering-science-in-a-crisis/ (visited on 17th June 2020).

Metzger, I. (3rd April 2020). 'Expertenpapier zu Corona: "100.000 zusätzliche Tote” sind möglich'. Kurier. URL: https://kurier at/politik/inland/expertenpapi er-zu-corona-100000-zusaetzliche-tote-sind-moeglich/400801484.

Metzler, H., Rimé, B. and Garcia, D. (2020). Expressions of emotions and social behavior around COVID-19 on Twitter in different countries.

URL: https://csh.ac . at/covid19/twitter/ (visited on 18th June 2020).

Munafò, M. (2016). 'Open science and research reproducibility'. ecancermedicalscience 10. https://doi.org/10.3332/ecancer.2016. ed56.

Österreichischer Rundfunk (12th March 2020a). Intensivbetten-Kapazität reicht noch 14 Tage. URL: https://science.orf.at/stories/3200192/ (visited on 11th August 2020).

- (17th April 2020b). Online-Emotionen: Mehr Trauer als Wut. URL: https://science.orf .at/stories/3200583/ (visited on 9th June 2020).

- (27th April 2020c). Regierungskommunikation: Aufregung über kolportierte Angststrategie. URL: https://orf . at/stories/3163480/ (visited on 22nd June 2020).

Pellert, M., Lasser, J., Metzler, H. and Garcia, D. (2020). 'Dashboard of sentiment in Austrian social media during COVID-19'. Frontiers in Big Data. https://doi.org/10.3389/fdata.2020.00032. arXiv: 2006.11158.

Plotly Technologies Inc. (2015). Collaborative data science. URL: https: //plot. Iy. rbb24 (2020). 'Das ist die Corona-Ampel - mit all ihren Schwierigkeiten'. rbb24. URL: https://www.rbb24.de/panorama/thema/2020/coronavirus/beitraege _neu/2020/05/corona-ampel-infektionen-berlin.html (visited on 23rd June 2020).

Renn, O. (2010). 'Risk communication: insights and requirements for designing successful communication programs on health and environmental hazards'. In: Handbook of risk and crisis communication. New York, NY, U.S.A.: Routledge, pp. 80-98. https://doi.org/10.4324/9780203891629.

Reynolds, B. and Quinn, S. C. (2008). 'Effective communication during an Influenza pandemic: the value of using a crisis and emergency risk communication framework'. Health Promotion Practice 9 (4 Suppl), 13S-17S. https://doi.org/10.1177/1524839908325267. 
Reynolds, B. and Seeger, M. W. (2005). 'Crisis and emergency risk communication as an integrative model'. Journal of Health Communication 10 (1), pp. 43-55. https://doi.org/10.1080/10810730590904571.

risklayer (2020). Risk layer explorer.

URL: http://www.risklayer-explorer.com/event/100/detail (visited on 23rd June 2020).

Sandman, P. and Lanard, J. (6th January 2005). Tsunami risk communication: warnings and the myth of panic. Peter Sandman/Jody Lanard column.

URL: https://www. psandman.com/col/tsunami1.htm (visited on 22nd June 2020).

Shore, R. (2013). 'Lessons from Fukushima: scientists need to communicate better'. Bulletin of the World Health Organization 91 (6), pp. 396-397. https://doi.org/10.2471/blt.13.030613.

Sprenger, M., Sorger, J., Knecht, W. and Knecht, M. (2020a). CSH Corona Traffic Light - Austria. URL: https://vis.csh.ac.at/corona-ampel/ (visited on 12th June 2020).

- (2020b). CSH Corona Traffic Light - global. URL: https://vis.csh.ac.at/corona-traffic-light/world/ (visited on 24th August 2020).

Stein, M. (2004). 'The critical period of disasters: insights from sense-making and psychoanalytic theory'. Human Relations 57 (10), pp. 1243-1261. https://doi.org/10.1177/0018726704048354.

van der Meer, T. G. L. A. and Jin, Y. (2020). 'Seeking formula for misinformation treatment in public health crises: the effects of corrective information type and source'. Health Communication 35 (5), pp. 560-575. https://doi.org/10.1080/10410236.2019.1573295.

Wang, D., Hu, B., Hu, C., Zhu, F., Liu, X., Zhang, J., Wang, B., Xiang, H., Cheng, Z., Xiong, Y., Zhao, Y., Li, Y., Wang, X. and Peng, Z. (2020). 'Clinical characteristics of 138 hospitalized patients with 2019 novel coronavirus-infected pneumonia in Wuhan, China'. JAMA 323 (11), pp. 1061-1069. https://doi.org/10.1001/jama.2020.1585.

Ware, C. (2019). Information visualization: perception for design. 4th ed. Cambridge, MA, U.S.A.: Morgan Kaufmann. ISBN: 978-0-12-812875-6. https://doi.org/10.1016/c2016-0-02395-1.

Weichhart, J. (24th March 2020). 'Kriminalität sinkt durch Corona: “Harte Zeiten für Einbrecher"'. kurier. URL: https://kurier .at/chronik/oesterreich/kriminal itaet-sinkt-durch-corona-harte-zeiten-fuer-einbrecher/400791605.

Wiener Zeitung Online (20th April 2020). ‘Gefühle und Videokonferenzen Wiener Komplexitätsforscher finden bei Online-Emotionen nach einem deutlichen Anstieg zu Beginn der Krise nun weniger Ängstlichkeit'. Wiener Zeitung. URL: https://www.wienerzeitung. at/nachrichten/wissen/mensch/2 057851-Gefuehle-und-Videokonferenzen. html (visited on 9th June 2020).

Wissenschaft im Dialog (2020). Wissenschaftsbarometer Corona Spezial. URL: https://www . wissenschaft-im-dialog. de/projekte/wissenschaftsbar ometer/wissenschaftsbarometer-corona-spezial/ (visited on 17th June 2020).

Zaki, J. (2020). 'Catastrophe compassion: understanding and extending prosociality under crisis'. Trends in Cognitive Sciences 24 (8), pp. 587-589. https://doi.org/10.1016/j.tics.2020.05.006. 
Ziemkiewicz, C. and Kosara, R. (2008). 'The shaping of information by visual metaphors'. IEEE Transactions on Visualization and Computer Graphics 14 (6), pp. 1269-1276. https://doi.org/10.1109/tvcg.2008.171.

\section{Authors}

Jana Lasser is a postdoctoral researcher in the field of computational social science in the section for Science of Complex Systems at Medical University of Vienna and the Complexity Science Hub Vienna. She received her Ph.D. in physics at the Max Planck Institute for Dynamics and Self-Organization, Germany in 2019. Her research activity focuses on the analysis of disease risk and emotion dynamics from several big longitudinal data sets. E-mail: lasser@csh.ac.at.

Verena Ahne is Head of Knowledge Transfer \& Dissemination at the Complexity Science Hub Vienna. Verena earned her master's degree in cultural anthropology, linguistics, philosophy, and science theory from the University of Vienna. From 2000 to 2017 she worked as a freelance science, health, and medical writer mainly for Austrian and German quality media like Gehirn\&Geist, Die Zeit, profil, profil Wissen, Die Presse, Der Standard, Heureka, UNIVERSUM Magazin, Terra Mater Magazin, among others. E-mail: ahne@csh.ac.at.

Georg Heiler has been a Ph.D. candidate at TU Wien and the Complexity Science Hub Vienna since 2018. Georg obtained a bachelor's and master's degree in economics in business informatics from TU Wien. In his master thesis, entitled "Cost-based statistical methods for fraud detection", he showed the superiority of a machine learning based credit check process over traditional methodologies at a partner company. E-mail: heiler@csh.ac.at.

Peter Klimek is associate professor at the section for Science of Complex Systems at the Medical University of Vienna and Faculty member of the Complexity Science Hub Vienna. Peter obtained his Ph.D. in theoretical physics in 2010 and his master in 2007 in quantum information. His research interests include medical data science, complexity economics and socio-economic modelling \& simulation. E-mail: peter.klimek@meduniwien.ac.at.

Hannah Metzler is a postdoctoral researcher at the Complexity Science Hub Vienna and the Public Health Centre at Medical University of Vienna. After studying psychology at the University of Vienna, she did her Ph.D. in cognitive neuroscience at Sorbonne University and École Normale Supérieure in Paris. In her current research, Hannah applies social computational science approaches to investigate online social interaction and mental health, including collective emotions, and potential contributions of the media to suicide prevention.

E-mail: metzler@csh.ac.at.

Tobias Reisch is a Ph.D. candidate at the section of Science of Complex Systems at the Medical University of Vienna and the Complexity Science Hub Vienna. Tobias received his bachelor's and master's degree in physics from the TU Vienna. Tobias' research interests are centered around data analysis and econophysics. He is working on new models to understand economic development and innovation by investigating supply chains. E-mail: tobias.reisch@vol.at. 
Martin Sprenger received his Ph.D. in medicine in 1994 from the University of Graz, Austria and his Master of Public Health in 2002 from the Department of Community Health in Auckland, New Zealand. Currently he is the head of the ULG Public Health at the Medical University of Graz. His current research focus includes prevention, primary care and public health.

E-mail: martin.sprenger@medunigraz.at.

Stefan Thurner is full professor for Science of Complex Systems at the Medical University of Vienna. He is external professor at the Santa Fe Institute, senior researcher at IIASA, and president of the Complexity Science Hub Vienna. Stefan obtained a Ph.D. in theoretical physics from the TU Vienna and a Ph.D. in economics from the University of Vienna. Stefan started his career with contributions to theoretical particle physics and gradually shifted his research focus to the understanding of complex systems.

E-mail: stefan.thurner@meduniwien.ac.at.

Johannes Sorger is a postdoctoral researcher in Data Science and Visualization at the Complexity Science Hub Vienna. Johannes received his computer science degree in visual computing from the TU Wien at the Institute of Computergraphics and Algorithms where he also obtained his Ph.D. in a collaboration with the VRVis research center. Johannes' main research interests are centred around the application of visualisation as an enabling technology - to support decision making processes and the dissemination of knowledge. E-mail: sorger@csh.ac.at.

\section{How to cite}

Lasser, J., Ahne, V., Heiler, G., Klimek, P., Metzler, H., Reisch, T., Sprenger, M., Thurner, S. and Sorger, J. (2020). 'Complexity, transparency and time pressure: practical insights into science communication in times of crisis'. JCOM 19 (05), N01. https://doi.org/10.22323/2.19050801. 